\title{
COMPARISON OF FIRST YEAR MEDICAL UNDERGRADUATES' PERCEPTIONS REGARDING THEIR RESPECTIVE INSTITUTIONAL EDUCATIONAL ENVIRONMENT IN INTEGRATED VS TRADITIONAL MEDICAL CURRICULUM BY USING DREEM INVENTORY
}

\section{Tatheer Zahra ${ }^{\mathrm{I}}$, Mohammad Iqbal Khan ${ }^{2}$, Muhammad Umer ${ }^{3}$, Hijab-e-Zainab ${ }^{4}$}

\section{ABSTRACT}

OBJECTIVE: To compare the first-year medical undergraduates' perceptions regarding their institutional educational environment in traditional and integrated medical curricula by using the Dundee Ready Educational Environment Measure (DREEM) inventory.

METHODS: This cross-sectional comparative study was conducted in 201718 at two medical institutions of Rawalpindi and Islamabad labeled as Institution $A$ (with integrated curriculum) and B (with traditional curriculum). After seeking written informed consent, paper format DREEM questionnaire was administered to 100 first year MBBS students. Data was analyzed using SPSS version 24. Descriptive and inferential statistics were applied.

RESULTS: Mean global DREEM score for institution A was I $31.09 \pm 19.94$ with minimum score of 87 and maximum score of I 75. Mean global DREEM score for institution $B$ was I I $7.11 \pm 21.02$ with minimum score of 65 and maximum score of I67. These scores reveal a "more positive" environment (scores of I0I-I50), with no statistically significant difference $(p$-value $>0.05)$ between them. DREEM subscales scores for both institutions indicated room for improvement at both institutions in all five domains.

CONCLUSION: We concluded that there were no statistically significant differences between first year medical students' perceptions of their respective institutional educational environment in integrated versus traditional medical curriculum by using DREEM. However, students in integrated medical curriculum perceived their educational environment more positively than their counterparts in traditional medical curriculum.

KEY WORDS: Educational environment (Non-MeSH); Students, Medical (MeSH); Traditional curriculum (Non-MeSH); Integrated curriculum (Non$\mathrm{MeSH})$; DREEM(Non-MeSH).

THIS ARTICLE MAY BE CITED AS: Zahra T, Khan MI, Umer M, Hijab-eZainab. Comparison of first year medical undergraduates' perceptions regarding their respective institutional educational environment in integrated vs traditional medical curriculum by using DREEM inventory. Khyber Med Univ J 2020; I3(1):97-102. https://doi.org/I0.35845/kmuj.2021.20920.

\section{INTRODUCTION}

E ducational environment plays substantial role in students' learning, motivation, behavior, self-esteem, academic achievement, successful future career choices and a sense of overall well-being. ${ }^{1-2}$ The learning environment is defined as "everything that happens within the classroom or teaching space, department, faculty, campus or university", which is essential in determining the success of undergraduate medical education. ${ }^{3}$ Learners' perceptions of several connotations of the learning environment, such as the physical, virtual, intellectual or social, psychological or emotional etc., have profound impact upon their responses to learning processes. ${ }^{4}$ Genn highlights that while the educational environment seems rather intangible, unreal and insubstantial; but its effects are pervasive, real, substantial and influential. $^{5}$ Even slightly changing the physical structure of a teaching and
I: Shifa College of Medicine (SCM), Shifa Tameer-e-Millat University (STMU), Sector H-8/4, Islamabad, Pakistan

2: Department of Medical Education, Shifa Tameer-eMillat University, Islamabad, Pakistan

3: Rawalpindi Medical University and Allied Hospitals, Rawalpindi, Pakistan

4: Federal Medical \& Dental College (FMDC), Islamabad, Pakistan

Contact \# +92-300-8148250

Email区: drtatheer@gmail.com; tatheer.scm@stmu.edu.pk

Date Submitted: October II, 2020

Date Revised: May II, 2021

Date Accepted: May 14,2021

learning setting, a unique tactic to modify the educational environment, strongly influences learners' perceptions. ${ }^{6}$

Several instruments have been devised for measuring learning environment in medical institutions in the past few decades. These include Symptom Questionnaire (SQ), Learning Environment Questionnaire (LEQ), Medical School Learning Environment Survey (MSLES) etc., These instruments have their own strengths and weaknesses both about their design and psychometric properties. ${ }^{7}$ However, these turned out to be outdated for new millennium by not considering of third generation curriculum reforms as proposed by the Global Independent Commission on Education for Health Professionals for $21^{\text {st }}$ century published in The Lancet report in December 2010 at Bangkok. A revival of interest been observed owes to the recent imperatives towards enhanced quality in health professions education. ${ }^{910}$ Dundee Ready Educational Environment Measure (DREEM) inventory claims to be a valid, reliable, generic, multidimensional tool for measuring educational environment with excellent psychometric properties, particularly at undergraduate level..$^{11-13}$ Besides, being the significant component of program appraisal, it provides a comprehensive account of strengths 
TABLE I: MEAN GLOBAL DREEM SCORES AND SUBSCALES FOR INSTITUTIONS A AND B

\begin{tabular}{|c|c|c|c|c|c|c|c|c|}
\hline \multirow[b]{2}{*}{ \# } & \multirow[b]{2}{*}{ Scores } & \multirow[b]{2}{*}{$\begin{array}{l}\text { Max. } \\
\text { Score }\end{array}$} & \multicolumn{3}{|c|}{ Institution A } & \multicolumn{3}{|c|}{ Institution B } \\
\hline & & & Mean $\pm S D$ & $\begin{array}{l}\% \text { of } \\
\text { Max. } \\
\text { score }\end{array}$ & Interpretation & Mean \pm SD & $\begin{array}{l}\text { \% of } \\
\text { Max. } \\
\text { score }\end{array}$ & Interpretation \\
\hline 1 & $\begin{array}{l}\text { Total } \\
\text { DREEM }\end{array}$ & 200 & $131.09 \pm 19.94$ & 65.5 & $\begin{array}{l}\text { More positive } \\
\text { than negative }\end{array}$ & $117.11 \pm 21.02$ & 58.5 & $\begin{array}{l}\text { More positive } \\
\text { than negative }\end{array}$ \\
\hline 2 & SPOL & 48 & $32.67 \pm 6.11$ & 68.06 & $\begin{array}{l}\text { A more positive } \\
\text { perception }\end{array}$ & $28.57 \pm 6.08$ & 59.52 & $\begin{array}{l}\text { A more positive } \\
\text { perception }\end{array}$ \\
\hline 3 & SPOT & 44 & $30.52 \pm 4.43$ & 69.36 & $\begin{array}{l}\text { Moving in the } \\
\text { right direction }\end{array}$ & $25.59 \pm 5.45$ & 58.16 & $\begin{array}{l}\text { Moving in the } \\
\text { right direction }\end{array}$ \\
\hline 4 & SASP & 32 & $20.78 \pm 4.6 I$ & 64.94 & $\begin{array}{l}\text { Feeling more on } \\
\text { the positive side }\end{array}$ & $19.84 \pm 4.02$ & 62 & $\begin{array}{l}\text { Feeling more on } \\
\text { the positive side }\end{array}$ \\
\hline 5 & SPLA & 48 & $31.62 \pm 5.84$ & 65.87 & $\begin{array}{l}\text { A more positive } \\
\text { atmosphere }\end{array}$ & $27.73 \pm 6.39$ & 57.77 & $\begin{array}{l}\text { A more positive } \\
\text { atmosphere }\end{array}$ \\
\hline 6 & SSSP & 28 & $15.51 \pm 3.85$ & 55.39 & Not too bad & $15.39 \pm 3.77$ & 54.96 & Not too bad \\
\hline
\end{tabular}

and weaknesses of a curriculum. of the corrective strategies. FurtherMeasuring students' perceptions by using DREEM has been utilized as diagnostic inquiries allowing quality assurance evaluations to be made between programs as well as within different modules of a program. ${ }^{14}$

Most public sector medical schools in Pakistan have adopted traditional medical curriculum. Nevertheless, few institutions in private sector have implemented system-based integrated modular curriculum e.g., The Aga Khan University (AKU), Shifa Tameer-eMillat University (STMU) and Riphah International University (RIU) etc. However, there is scarcity of comparative studies regarding undergraduates' perceptions of their institutional educational environment in traditional vs. integrated curriculum both locally and globally. ${ }^{15-16}$ The aim of the present study was to compare the first-year medical undergraduates' perceptions regarding their institutional academic environment in traditional vs. integrated medical curriculum by using the DREEM inventory at two institutions of Rawalpindi/ Islamabad located in the north of Pakistan. The results may be used 'diagnostically' to identify strengths and weaknesses of the respective institutions' educational environments as perceived by their respective students. By utilizing these results 'therapeutically', respective medical educationists along with policy makers may rationalize and optimize their priorities for necessary future interventions in terms of resources allocation and curricular reforms to maximize educational output. Besides, this data will serve as a baseline to help subsequent studies to perceive results more, it will supplement the academic research and scholastic literature in the field of medical education especially in the context of Pakistan.

\section{METHODS}

This cross-sectional comparative study was conducted in 2017-18 at two institutions of Rawalpindi and Islamabad i.e., one following integrated (Institution A) and the other following traditional (Institution B) medical curricula. Ethical approval was sought and received for the present study from Institutional Review Board (IRB) of both institutions (IRB reference \# 679-I25-2016). Written informed consent was obtained from all the participants of this study and their participation was voluntary.

"Power Analysis Formula" was used to calculate sample size. ${ }^{17}$ It was estimated that a minimum of "65 students" were needed for each of our two groups. Hundred first year MBBS students from each institution $A$ and $B$ were enrolled who have spent at least 6 months in these institutions and gave informed written consent. Persons who did not meet this inclusion criteria were excluded from our study. Institution with integrated curriculum i.e., institution $A$ had an annual intake of 100 first year medical students. All the target population was enrolled in this study and there was no sampling technique applied in this case. Whereas the institution with traditional curriculum i.e., institution $B$ had intake of around 300 first year medical students per year. Then, we selected target population of 100 participants by using the "lottery method" of simple random sampling. The DREEM inventory comprising of 50 closed-ended questions was used to collect data." Since, all participants were well versed and competent in English language, an Internationally validated English version of DREEM was applied to avoid any respondent's bias due to translation of instrument. ${ }^{13}$ Prior to data collection, a pilot study was conducted on subjects from a different year of study other than the population selected to assess the clarity and uniform interpretation of the questions. The pilot study sample was not included in the main study.

The 50 items of DREEM questionnaire have been distributed among five domains: students' perceptions of learning (SPOL), students' perceptions of teachers (SPOT), students' academic selfperceptions (SASP), students' perceptions of learning atmosphere (SPLA), and students' social self-perceptions (SSSP). Out of the 50 items, 4 I were scored on a five-point Likert scale from 0 (strongly disagree) to 4 (strongly agree). The remaining 9 items $(4,8,9,17,25,35,39$, 48 and 50) were negative statements and were scored in reverse order for analyses i.e., invert scores. Ascore of 0 is the lowest and a very distressing. The maximum score is 200 representing greater satisfaction with one's educational environment. DREEM subcategories are considered more realistic to measure the overall motivation and learning attitude of students. Ranges provided by McAleer and Roff 18 were used as standard reference.

Data was gathered by guided selfadministered questionnaire to all eligible participants towards the mid of their first year to maximize response rate. A minimum of an hour session slot was requested in first year timetable. A brief orientation was given to student, 
TABLE II: THE INDEPENDENT SAMPLE t-TEST TO COMPARE GROUP STATISTICS BETWEEN INSTITUTIONS A AND B

\begin{tabular}{|c|c|c|c|c|c|c|c|}
\hline Scores & Institution & $\mathbf{N}$ & Min. & Max. & X土S.D. & SEM & p-value ${ }^{*}$ \\
\hline \multirow{2}{*}{ SPOL } & $A$ & 97 & 16 & 48 & $32.67 \pm 6.106$ & 0.620 & \multirow{2}{*}{0.96} \\
\hline & B & 97 & 12 & 44 & $28.57 \pm 6.076$ & 0.617 & \\
\hline \multirow{2}{*}{ SPOT } & A & 97 & 20 & 41 & $30.52 \pm 4.433$ & 0.450 & \multirow{2}{*}{0.12} \\
\hline & B & 97 & 8 & 38 & $25.59 \pm 5.450$ & 0.553 & \\
\hline \multirow{2}{*}{ SASP } & $\mathrm{A}$ & 97 & 9 & 31 & $20.78 \pm 4.608$ & 0.468 & \multirow{2}{*}{0.17} \\
\hline & $\mathrm{B}$ & 97 & 10 & 28 & $19.84 \pm 4.015$ & 0.408 & \\
\hline \multirow{2}{*}{ SPLA } & $\mathrm{A}$ & 97 & 18 & 46 & $31.62 \pm 5.844$ & 0.593 & \multirow{2}{*}{0.25} \\
\hline & B & 97 & 13 & 44 & $27.73 \pm 6.389$ & 0.649 & \\
\hline \multirow{2}{*}{ SSSP } & A & 97 & 2 & 23 & $|5.5| \pm 3.486$ & 0.391 & \multirow{2}{*}{0.59} \\
\hline & $B$ & 97 & 1 & 23 & $15.39 \pm 3.77 \mid$ & 0.383 & \\
\hline \multirow{2}{*}{$\begin{array}{l}\text { Total } \\
\text { DREEM }\end{array}$} & $A$ & 97 & 87 & 175 & $131.09 \pm 19.936$ & 2.024 & \multirow{2}{*}{0.60} \\
\hline & $B$ & 97 & 65 & 167 & $117.11 \pm 21.025$ & 2.135 & \\
\hline
\end{tabular}

*Independent sample t-test; $A=$ Institution with Integrated curriculum; $B=$ Institution with Traditional curriculum; $N=$ Number of respondents; Min. $=$ Minimum; Max. $=$ Maximum; $X=$ Mean; SEM $=$ Standard Error of Mean.

enlightening the purpose of the study, procedures involved and details regarding DREEM inventory. Furthermore, it was addressed that this data would be used for research, quality assurance and educational purposes. After seeking the written informed consent of enrolled participants, data was collected from the willing participants. It was emphasized that the identity of the participants would remain anonymous, and the data would not be able to be tracked back to the students. Researchers were present throughout the data collection process to answer any queries of respondents in case clarification required about statements or educational terms used in the questionnaire.

All the ethical principles pertaining to data protection were strictly followed throughout data collection process. Duly filled questionnaires were handled and stored in accordance with the tenets of the Helsinki Declaration. All questionnaires were manually checked and edited for completeness. The data collected was plotted in Microsoft Excel Spreadsheets in a password protected computer for statistical analysis. All data kept electronically was accessible to the principal investigator and co-investigators only, who were responsible for ensuring its confidentiality and privacy.

Prior to data analysis, normality of distribution was confirmed. The data was regrouped according to the five domains, as questions about perception were in different locations in the original questionnaire. Data analysis was carried out using both Microsoft Office Excel 2010 (Microsoft Co., Redmond, WA, USA) and SPSS version 24 (SPSS Inc.,
Chicago, IL, USA) for Windows. Descriptive statistics were employed. Summary statistics yielded mean total DREEM score for 50 -items and mean scores for each of its five subscales (SPOL, SPOT, SASP, SPLA, and SSSP) for both institutions. Using inferential statistics, independent samples, t-test was applied to compare group means for institutions $A$ and $B$. Results were statistically significant at a $p$-value $<0.05$.

\section{RESULTS}

Out of 100 participants from institution A, 98 were present in data collection session and gave their consent. From institution $B, 100$ students participated in the study. Incomplete questionnaires led to the drop out of four students in total; three from institution $B$ (out of 100 participants) and one from institution A (out of 98 participants); indicating total response of 97 participants each from Institution $A$ and B ( $97 \%$ response rate).

Mean global DREEM score for institution A was 1 31.09 19.94 (range 87- I75) and for institution B was $117.11 \pm 21.02$ (range 65-167). These scores reveal a "more positive" environment (scores of I0I-I50) [Table I]. SPOL scores for institutions $A$ and $B$ were $32.67 \pm 6.11$ (range 16-48) and 28.57 \pm 6.08 (range 12-44) respectively. Use of score descriptors for the subscale scores for the DREEM revealed that students' perception of learning (SPOL) was a "more positive perception" (scores of 25-36). SPOT scores for institutions $A$ and $B$ were $30.52 \pm 4.43$ (range 20-4I) and $25.59 \pm 5.45$ (range 8-38) respectively, indicating "moving in the right direction" (scores of 23-33). SASP scores for institutions $A$ and $B$ were $20.78 \pm 4.61$ (range 9-3I) and $19.84 \pm 4.02$ (range 10-28) respectively. It revealed that SASP were "feeling more on the positive side" (scores of 17-24). SPLA scores for institutions $A$ and $B$ were $31.62 \pm 5.84$ (range 18-46) and $27.73 \pm 6.39$ (range 13-44) respectively, which disclosed "more positive atmosphere" (scores of 25-36). SSSP scores for institutions $A$ and $B$ were $|5.5| \pm 3.85$ (range 2-23) and 15.39 \pm 3.77 (range I-23) respectively, meaning "not too bad" (scores of I 5-2I).

Independent sample t-test was applied to compare institution $A$ and institution $B$. There was no statistically significant difference $(p>0.05)$ in mean global DREEM score and its entire five subscales between the two institutions (Table II).

\section{DISCUSSION}

Learning environment is an aggregate of the internal and external conditions surrounding and affecting learning process. ${ }^{5-6}$ Besides ambience and up-todate technology, it includes educational organization's culture, vision and mission, curriculum design, instructional strategies, instructors' behavior, the social, emotional and academic environment, and psychological support system available to students during anxiety and stress etc.. ${ }^{7}$ The main objective of the present study was to compare the first year MBBS student's perceptions regarding their institutional learning environment in an integrated versus traditional medical curriculum by using a valid and reliable quantitative survey tool the DREEM.

Response rate (97\%) and volunteerism 
among participants is commendable in our study comparing with previous studies using DREEM ranged from $45 \%$ to $100 \% .^{10-15,19-22}$ High response rate and adequate sample size reported in current study, despite the freedom of choice to evade, was an indication of learners' confidence and trust upon the survey techniques. Brief introduction given to students regarding the aim of this study might have encouraged them and led them to think that the results of such study would proceed to significant changes in their learning. Above and beyond, it might be a sign of the learners' desire to share their opinions about learning environment to bring positive change. Most of the students had responded to all the items verifying that DREEM favorable, user friendly and relevant. Besides, sufficient time required to fill the survey forms indicated that the DREEM inventory was practical to use in Pakistan.

Total DREEM scores for institutions A and B were $131.09 / 200$ (65.54\%) and II7.II/200 (58.55\%) respectively. DREEM global mean scores for both institutions were optimistic demonstrating more positive aspects than negative about education environment as per the interpretation suggested in the literature. ${ }^{18}$ Although, there is no objective consensus on the adequate or standard DREEM questionnaire scores from available literature. Yet, a range of DREEM scores (90/200-140/200 45.0$70.0 \%$ ) have been reported from studies on medical undergraduates.' Our learners' perspectives compared satisfactorily with studies conducted internationally. Such positive outcome was encountered by other scholars as well who used DREEM questionnaire for undergraduate students in various countries including Nigeria, Pakistan, KSA, UK, Malaysia, Germany, Greece, Iran, Ireland, Australia, New Zealand, India and Sri Lanka. ${ }^{9-16,19-23}$ Despite the differences in study settings (in terms of varying cohorts of participants from different study levels, curriculum, ethnic backgrounds, and multiple undergraduate and postgraduate courses related to health sciences), the mean scores ranged well within the range $10 \mathrm{I}-150$ as ours which indicated a "more positive than negative" perception of environment at both institutions $\mathrm{A}$ and $\mathrm{B}$.

Results of inferential statistics revealed no statistically significant difference ( $p$ value $>0.05$ ) between first year medical students' perceptions of their respective institutional educational environment in integrated versus traditional medical curriculum by using the DREEM. Although, there is no statistically significant difference in the mean total DREEM scores; yet this study validates that student in integrated medical curriculum perceived their educational environment more positively $(13 \mid / 200)$ than their counterparts in traditional medical curriculum (1 I 7/200). The better mean global DREEM scores for institution $A$ with integrated curriculum as compared to their counterparts in institution B reflected student's satisfaction with student-centered curriculum. It has also been perceived that learner in innovative curricula tend to show more contentment with their learning environments, compared to students of the traditional curriculum. ${ }^{4}$ Higher DREEM scores highlighted the significance of modern student-centered curriculum and its progressive effects on student's perception of learning environment. Many studies had a higher mean global DREEM score than the institution $A$ in the present study which may reflect that these institutions were equally progressive in terms of providing a student-centered approach to education. ${ }^{23}$ However, much effort is needed to achieve the standards of education as set by Roff $\mathrm{S}$, et al..' Furthermore, it has been suggested that medical and dental schools offering traditional curricula generally tend to report lower total DREEM scores (usually score < I20). ${ }^{13}$ The results of our study have supported this notion.

The mean scores for all the five DREEM subscales revealed positive perception $(>50 \%)$ by the students at both institutions. It was specified that most participants settled to a "more positive perception" regarding their perception of learning (SPOL), "moving in the right direction" for perception of teachers (SPOT), feeling "more on the positive side" for their academic self-perception (SASP), feeling "more on the positive side" for the perception of atmosphere
(SPLA), and reported "not too bad" for the social self-perceptions (SSSP). In a nutshell, the subscale scores for both institutions were placed in the second tier, a phase below the perfect one. These results matched with the findings published in previous studies from various other institutions. ${ }^{9,24}$ There was no statistically significant difference $(p$ $>0.05)$ in DREEM five subscales between institution $A$ and institution $B$. However, institution A had better DREEM subscales scores as compared to their counterparts in traditional medical curriculum (table II).

The highest scoring contributory subscales for institution A was SPOT with $69.36 \%$ as compared to institution B with $58.16 \%$ (table I). It has suggested that teachers at institution $A$ were highly qualified and well trained in terms of their interactions with both students and patients. Students' perceptions of faculty have a direct and lasting psychological effect on the students and the learning environment. It is described as the chief determinant of the success of a curriculum. ${ }^{5-6}$ Since, teachers are considered "role models" for the students. Their attitudes can ultimately affect their learners. Consequently, teachers must participate frequently in continuing medical education (CME) activities of faculty development and training. Highest scores in this domain are contrary to the findings of Al-Hazimi A, et al. who reported lowest scores for SPOT. ${ }^{19}$ However, our findings correspond with the results of Rehman et al. who reported SPOT as the best cataloged domain. ${ }^{15}$ The highest scoring (62\%) contributory domain for institution B was SASP (table I). Nevertheless, institution $A$ had revealed better scores for this domain (64.94\%). Academic self-perception of students' is defined as learners' self-concepts in terms of perceptions formed through experience with and interpretations of one's environment. ${ }^{25}$

The lowest scoring contributory subscales for both institutions $A$ and $B$ was student's social self-perceptions (SSSP) with sores of $55.39 \%$ and $54.96 \%$ respectively (table I), which could be attributed to stress, boredom, and the exhaustion. Although, students reported to have good friends; but they 
did not have a good social life. Again, the hectic timetables leave no time to socialize in at the campus. It is a point of concern both for administration and faculty. These findings were attributed to either the lack of student support system or an overloaded curriculum. A similar observation was reported among medical students in Pakistan ${ }^{26}$ and worldwide. ${ }^{16}$ Since, students are among the principal stakeholders; hence their concerns must be addressed. In this regard, both institutions need to support the students and create enabling environment that endorses healthy social communication and cocurricular/leisure activities.

The substantial strength of our crosssectional comparative study included adequate sample size and high response rate at both institutions. It indicated good co-operation of students in terms of their time and feedback comments. Besides, the DREEM questionnaire was used in its original form and language (i.e., in English) with unswerving high reliability.

The major limitation of this study was that it presented perceptions of only first year MBBS students. Their views were indiscriminate if we would have considered all medical students of these two institutions. Besides, data collection was limited to merely two medical institutions in the region of Rawalpindi/ Islamabad, which cannot be generalized to all institutions of Pakistan since each institution has its own unique learning environment.

However, it is suggested to conduct the similar studies on a larger scale covering as many aspects as possible such as perceptions of teachers/staff and parents, association with academic achievements and levels of learners' stress, etc.

\section{CONCLUSION}

The present study revealed that first year medical students of both institutions perceived their educational environment positively. Although, there was no statistical difference reported; nevertheless, the perceptions of participants at institution A with integrated medical curriculum were somewhat better than their counterparts at institution B with traditional medical curriculum. This study also revealed areas of improvement in educational environment for both institutions, which would enable the respective stakeholders to adopt remedial measures accordingly. Since, the educational environment affects learners' motivation and achievement, it is imperative to document first year medical student's views vis-à-vis their educational environment.

\section{ACKNOWLEDGMENTS}

The authors are extremely grateful to all the participants of this study who took out time from their hectic schedules and gave honest feedback. We acknowledge the co-operation of the research department of both the institutions.

\section{REFERENCES}

I. Rania N, Siri A, Bagnasco A, Aleo G, Sasso L. Academic climate, wellbeing and academic performance in a university degree course. J Nurs Manag 20I4; 22: 75I-60. 20I4;22: 751-60. https://doi.org/10.1111/ j.1365-2834.20I2.0I47I.x

2. Gupta S, Jain A, Garg S, Sood S, Kumari B. Perceptions of Indian dental hygiene students toward their profession and its relationship with their explicit self-esteem scores. Indian J Dent 20I4; 5:202-10. https://doi.org/10.4103/0975962X. 144728

3. Qin Y, Wang Y, Floden RE. The Effect of Problem-Based Learning on Improvement of the Medical Educational Environment: A Systematic Review and Meta-Analysis. Med Princ Pract 2016; 25:52532. https:// doi.org/10. I I 59/000449036

4. Hammond SM, O'Rourke M, Kelly M, Bennett D, O'Flynn S. A psychometric appraisal of the DREEM. BMC Med Educ 2012; 12: 2. https:// doi.org/10.1 I86/1472-6920-12-2

5. Genn JM. AMEE Medical Education Guide No. 23 (Part I): Curriculum, environment, climate, quality and change in medical educationa unifying perspective. Med Teach 200I;23(4):337-44. https://doi.org/ I0.1080/0|42I590|20063330

6. Genn JM. AMEE Medical Education
Guide No. 23 (Part 2): Curriculum, environment, climate, quality and change in medical educational unifying perspective. Med Teach 2001;23(5): 445-54. https://doi.org/ I0.1080/0I42I590I 2007566 I

7. Dent J, Harden R. A Practical Guide for Medical Teachers. $4^{\text {th }}$ ed. Edinburgh: Churchill Livingstone Elsevier; 2013.

8. Frenk J, Chen L, Bhutta ZA, Cohen J, Crisp N, Evans T, et al. Health professionals for a new century: transforming education to strengthen health systems in an interdependent world. Lancet 2010;376(9756): 1923-58. https://doi.org/ 10.1016/S0|40-6736(10)61854-5

9. Miles S, Swift L, Leinster SJ. The Dundee Ready Education Environment Measure (DREEM): A review of its adoption and use. Med Teach 2012; 34: e62034. https://doi.org/ I0.3109/0142I59X.2012.668625

10. James D, Mani S, Mathew A, Velusamy SK. Perceptions of the educational environment at entry and exit of medical students to clinical teaching in a rural medical college. Int J Res Med Sci 20 I 7;5(6): 260I-7. https://doi.org//0.18203/ 2320-60I2.ijrms20I72455

I I. Mogre V, Amalba A. Psychometric properties of the Dundee ready educational environment measure in a sample of Ghanaian medical students. Educ Health 2016;29: 1624. https://doi.org/10.4/03/13576283. 178921

12. Roff S, McAleer S, Harden R, AlQahtani M, Ahmed AU, Deza H, et al. Development and validation of the Dundee Ready Education Environment Measure (DREEM). Med Teach 1997;19(4):295-9. https://doi.org/10.3109/01421599 709034208

13. Roff S. The Dundee Ready Educational Environment Measure (DREEM): A generic instrument for measuring students' perceptions of undergraduate health professions curricula. Med Teach 2005;27(4): 3225. https://doi.org/10.1080/ 0I42I590500I51054 
14. Soliman MM, Sattar K, Alnassar S, Alsaif F, Alswat K, Alghonaim M, et al. Medical students' perception of the learning environment at King Saud University Medical College, Saudi Arabia, using DREEM Inventory. Advan Med Educ Pract 2017;8;22I-7. https://doi.org/ 10.2147/AMEP.SI27318

15. Rehman R, Ghias K, Fatima SS, Hussain M, Alam F. Students' perception of educational environment at Aga Khan University Medical College, Karachi, Pakistan. Pak J Med Sci 2016;32(3):720-4. https://doi.org/10.12669/pjms.323. 9562

16. Zawaai $A H$, Elzubeir M. Using DREEM to compare graduating students' perceptions of learning environments at medical schools adopting contrasting educational strategies. Med Teach 20I2;34(I Suppl):25-31. https://doi.org/ I0.3109/0I42I59X.2012.656747

17. Creswell JW. Research Design Qualitative, Quantitative, and Mixed Methods Approach $4^{\text {th }}$ Edition. Sage Publications Inc.; 2014.

18. McAleer S, Roff S. A practical guide to using the Dundee Ready Education Environment Measure (DREEM).
In J. M. Genn (Ed.), Curriculum, environment, climate, quality and change in medical education: A unifying perspective (pp. 29-33). AMEE Education Guide no. 23. Scotland: AMEE.

19. Al-Hazimi A, Zaini R, Al-Hyiani A, Hassan N, Gunaid A, Ponnamperuma $G$, et al. Educational environment in traditional and innovative medical schools: A study in four undergraduate medical schools. Educ Health (Abingdon) 2004;17(2): 192-203. https://doi.org/10.1080/135762804 10001711003

20. Khan JS, Tabassum S, Yousafzai UK, Mukhtar O. Measuring the medical education environment in undergraduate medical colleges across Punjab, Pakistan. Biomedica 20 I I;27: I4-8.

2I. Imran N, Khalid F, Haider, II, Jawaid M, Irfan M, Mahmood A, et al. Student's perceptions of educational environment across multiple undergraduate medical institutions in Pakistan using DREEM inventory. J Pak Med Assoc 20I 5; 65(I): 24-8.

22. Ali K, Raja M, Watson G, Coombes L, Heffernan E. The dental school learning milieu: students' perceptions at five academic dental institutions in Pakistan J Dent Edu 2012;

$$
\text { 76(4): 487-94. }
$$

23. Brown T, Williams B, Lynch $M$. The Australian DREEM: evaluating student perceptions of academic learning environments within eight health science courses. Int J Med Educ 20II;2:94-I0I. https://doi. org/I0.5 I I6/ijme.4e66. Ib37

24. Bakhshi $\mathrm{H}$, Bakhshialiabad $\mathrm{MH}$, Hassanshahi GH. Students' perceptions of the educational environment in an Iranian Medical School, as measured by The Dundee Ready Education Environment Measure. Bangladesh Med Res Counc Bull 20I4; 40: 36-4I. https://doi.org/ I0.3329/bmrcb.v40il .20335

25. Mahsood N, Jamil B. Student perceptions of educational environment at institute of Public Health and Social Sciences, Khyber Medical University. Adv Health Prof Educ 20I5; I (2):60-4.

26. Nadeem A, Iqbal N, Yousaf A, Daud MA, Younis A. Students' perception of educational environment at Army Medical College, Rawalpindi: assessment by DREEM (DundeeReady Education Environment Measure). Pak Armed Forces Med J 20I4;64(2):298-303.

\section{AUTHOR'S CONTRIBUTION}

Following authors have made substantial contributions to the manuscript as under:

TZ: Conception and study design, acquisition of data, drafting the manuscript, critical review, approval of final version to be published

MIK: Acquisition of data, analysis and interpretation of data, drafting the manuscript, approval of final version to be published

MU: Acquisition of data, drafting the manuscript, approval of final version to be published

HeZ: Acquisition, analysis and interpretation of data, critical review, approval of final version to be published

Authors agree to be accountable for all aspects of the work in ensuring that questions related to the accuracy or integrity of any part of the work are appropriately investigated and resolved.

CONFLICT OF INTEREST
Authors declared no conflict of interest
GRANT SUPPORT AND FINANCIAL DISCLOSURE
Authors have declared no specific grant for this research from any
funding agency in the public, commercial or not-for-profit sectors
(20)
The data that support the findings of this study are available from the corresponding author upon reasonable request.

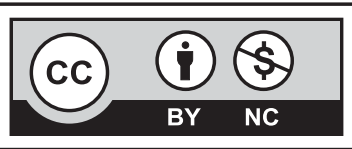

This is an Open Access article distributed under the terms of the Creative Commons Attribution-Non Commercial 2.0 Generic License. 